\title{
Estudantes negros ingressantes na universidade por meio de reserva de \\ vagas
}

Juliana Augusta Nonato de Oliveira*

Petronilha Beatriz Gonçalves e Silva **

* (Universidade Federal de São Carlos

- UFSCar, São Carlos-SP, Brasil)

** (Universidade Federal de São Carlos - UFSCar, São Carlos-SP, Brasil)
Resumo: 0 presente artigo é resultado de uma pesquisa de mestrado realizada com estudantes autodeclarados negros ingressantes na Universidade Federal de São Carlos por meio de um programa de ações afirmativas de reserva de vagas. Tal pesquisa teve como objetivos identificar processos educativos originados na vida universitária que contribuem ou prejudicam a construção e o fortalecimento da identidade negra e do pertencimento étnico-racial de raiz africana junto a tais estudantes, além de apontar sugestões que contribuam com o Programa de Ações Afirmativas da UFSCar na busca de estratégias de combate ao racismo. A coleta de dados ocorreu por meio de entrevistas semiestruturadas com três estudantes autodeclarados negros, duas mulheres e um homem, de diferentes cursos.

Palavras-chave: Ações afirmativas. Estudantes negros. Identidade negra. Pertencimento étnico-racial 
INTRODUÇÃO

Ao fazermos considerações sobre o Ensino Superior no Brasil, podemos evidenciar que desde o seu surgimento no país, esse nível de estudo foi destinado à elite brasileira, ou seja, a pessoas brancas descendentes de europeus, na maior parte dos casos, com alto poder aquisitivo. Entre as instituições de Ensino Superior estão as universidades, que, segundo Neves (2002), são instituições públicas ou privadas com diferentes tipos de cursos e programas, da graduação à pós-graduação, contemplando ensino, pesquisa e extensão integrados, incluindo mestrado, doutorado e cursos de especialização e aperfeiçoamento. Para cursá-la passa-se pela aprovação em algum tipo de processo seletivo.

Sabe-se, porém, que nem todos, notadamente pessoas oriundas dos grupos populares, conseguiam ter acesso aos estudos, mormente ao Ensino Superior.

Enquanto as classes mais favorecidas tinham a oportunidade de prolongar seus estudos, às classes menos favorecidas - entre essas a população negra, descendentes de africanos escravizados - eram destinadas oportunidades limitadas de estudos, o que lhes freava a ascensão social.

Gonçalves e Silva (2000) sublinham que durante boa parte do século XX, a educação dos negros ficou por conta da própria população negra e que, no pós-abolição, privilegiou-se enviar os meninos negros a patronatos agrícolas e as meninas a orfanatos, onde recebiam, essas, formação para serem empregadas domésticas. Por isso, significativa maioria de pessoas negras não teve, durante boa parte dos séculos XIX e XX, acesso aos bancos escolares. Os que aprenderam a ler, escrever ou até atingiam níveis mais elevados de estudos foram exceção, considerando-se o total da população negra.

A exclusão da população negra de determinados níveis de ensino vai contra o que está explicitado na Constituição Brasileira de 1988, a qual determina que a educação é um direito de todos e visa, entre outras coisas, o pleno desenvolvimento da pessoa para exercer a cidadania e estar qualificada para o mercado de trabalho. Além disso, segundo a Constituição, o ensino deve ser ministrado com base nos princípios de igualdade de condições para o acesso e permanência na escola.

Mesmo com iniciativas como a criação do ProUni e do Reuni ${ }^{1}$, que visam

O ProUni - Programa Universidade para Todos foi implementado pelo governo federal no ano de 2004 e institucionalizado pela Lei n. 11.096, em 13 de janeiro de 2005, sob o governo do então presidente Luiz Inácio Lula da Silva. 0 objetivo era, e ainda 
expandir o nível do Ensino Superior, a exclusão da população negra nesse nível de ensino ainda é evidente.

Os estabelecimentos de Ensino Superior brasileiros são compostos majoritariamente por pessoas brancas nos segmentos dos docentes, dos técnicos administrativos e, notadamente, entre os estudantes, muitos dos quais pertencem a grupos de alto poder aquisitivo. Tal exclusão, cultivada há tempos pela sociedade e seus estabelecimentos de ensino, mantém a população negra fora do Ensino Superior, o que garante a continuidade de uma sociedade excludente, em que pessoas negras são destinadas a posições inferiores em relação à população branca.

Segundo dados do Instituto Brasileiro de Geografia e Estatística (IBGE, 2010), a população branca de mais de 15 anos de idade tinha, em média, 8,4 anos de estudo em 2009, enquanto pretos e pardos apresentavam 6,7 anos. Nesse ano houve um aumento no número de anos de estudo em todos os grupos, porém, os níveis de estudo alcançados pela população preta e parda não superam os alcançados pela população branca há dez anos, ou seja, em 1999.

A proporção de estudantes de 18 a 24 anos de idade que cursam o Ensino Superior também mostra uma situação, em 2009, inferior para os pretos e pardos em relação à situação de brancos em 1999. Enquanto cerca de 2/3, ou $62,6 \%$ dos estudantes brancos estão nesse nível de ensino em 2009 , os dados mostram que há menos de $1 / 3$ nos outros dois grupos: $28,2 \%$ dos pretos e $31,8 \%$ dos pardos.

Nascimento (2006, p. 29) pondera que:

(...) se pode entender a ausência do negro no ensino superior: de um lado a pouca instrução que lhe é transmitida nos bancos escolares do ensino fundamental e médio; de outro o abandono dos estudos, por sentirem-se fora daquele mundo (...).

O autor afirma, ainda, que o sentimento de não se sentir parte do ambiente universitário é reforçado no próprio meio educacional, quando professores do Ensino Médio fazem profecias pessimistas, dizendo que seus alunos não irão para a universidade.

é, conceder bolsas de estudos integrais ou parciais a estudantes de baixa renda para frequentarem cursos de graduação em instituições privadas. Estabelece-se, também, que parte das bolsas seja destinada a pessoas com necessidades especiais, negros e indígenas (ALMEIDA, [s.d.]; CARVALHO, 2006). Já o Reuni - Programa de Apoio a Planos de Reestruturação e Expansão das Universidades Federais, foi regulamentado pelo Decreto Federal n. 6.096, de 24 de abril de 2007, prevendo apoiar a criação de novos cursos noturnos, aumento de vagas, inovações pedagógicas, bem como a criação de novas universidades federais (BORGES; AQUINO, 2012). 
Diante das circunstâncias, os estudantes negros projetam uma imagem da universidade como um lugar ao qual são impossibilitados de pertencer, fortalecidos por imagens propagadas por meios de comunicação televisivos ou impressos que indicam grupos de sucesso que podem estar no ambiente universitário, ou seja, pessoas jovens e brancas (LIMA, 2002).

A população negra, impedida de chegar ao Ensino Superior, além de não conquistar o diploma que traz prestígio social e oportunidade de compor os quadros de poder na sociedade, é excluída da chamada excelência acadêmica, sendo tal excelência do saber “[...] privilégio para poucos” (LIMA, 2002, p. 164), pois a excelência acadêmica se operacionaliza sob a forma de mérito individual e destina-se à elite branca de alto poder aquisitivo, que não encontra barreiras para acessar o Ensino Superior.

Diante de denúncias e reivindicações do Movimento Negro e de parte da sociedade civil em relação à extrema desigualdade racial apontada pelos indicadores sociais, ocasionadas por racismo e discriminação, começa a entrar em discussão no ano de 1995, sob o governo do então presidente Fernando Henrique Cardoso, a implementação de políticas de ações afirmativas.

Segundo Silva (2009, p. 264) ações afirmativas são:

\begin{abstract}
[...] um conjunto de metas articuladas e complementares que integram programas governamentais, políticas de Estado, determinações institucionais, com as finalidades de: corrigir desigualdades no acesso à participação política, educação, saúde, moradia, emprego, justiça, bens culturais; reconhecer e reparar crimes de desumanização e extermínio contra grupos e populações; reconhecer e valorizar a história, cultura e identidade de grupos sociais e étnico-raciais, bem como a importância de sua participação na construção de conhecimentos valiosos para toda a humanidade.
\end{abstract}

A extrema desigualdade entre negros e brancos no decorrer dos anos escolares, ao longo dos séculos, mostra que o estudante negro não está equiparado em oportunidades em relação ao estudante branco, o que muitas vezes é interpretado como incapacidade intelectual. Daí a necessidade de políticas de ações afirmativas direcionadas à população negra, na busca de acabar, entre outras coisas, com a sub-representação da população negra no Ensino Superior, que gera, segundo Queiroz (2010), desvantagem social, pois a escolaridade está diretamente relacionada às oportunidades de ingresso no mercado de trabalho e a condições mais dignas de vida. 


\section{PolíticAs de AÇÕES AFIRMATIVAS}

No ano de 2002, as universidades pioneiras em implantar programas de ações afirmativas destinados a estudantes negros foram a Universidade Estadual do Rio de Janeiro (Uerj), a Universidade Estadual do Norte Fluminense (Uenf) e a Universidade do Estado da Bahia (Uneb).

Outras instituições se seguem, como a Universidade de Brasília (UnB), primeira entidade mantida pelo poder público federal a adotar políticas de ações afirmativas para pessoas negras e indígenas, no ano de 2004, e a Universidade Federal de São Carlos (UFSCar), na qual se desenvolveu esta pesquisa, aprovando, no ano de 2006, um programa de ações afirmativas que contempla estudantes de baixa renda, negros e indígenas, sob a Portaria n. 695 , de 6 de junho de 2007.

Diante do crescente quadro de adoção de políticas de ações afirmativas por universidades públicas, muitas pessoas parecem não desejar que o quadro de desigualdade existente na sociedade se transforme, mostrandose extremamente contrárias a tais políticas, sobretudo em face da questão étnico-racial, proferindo muitos argumentos contrários, como, por exemplo, o de que tais políticas ferem o princípio da igualdade exposto na Constituição de 1988, na qual é decretado, em seu artigo 5ํㅜ que todas as pessoas são iguais perante a lei. $O$ argumento da inconstitucionalidade das políticas de ações afirmativas que utilizam critérios raciais, como no caso do questionamento sobre a política de cotas na UnB, foi derrubado por decisão unânime dos ministros do Supremo Tribunal Federal (STF) no mês de abril de 2012, ao julgarem que inconstitucional é não haver ações afirmativas, já que o que está expresso na Constituição é a igualdade, e tais políticas buscam garantir igualdade em um contexto de desigualdades.

Outro ganho para a sociedade foi a aprovação pelo Senado, em 7 de agosto de 2012, de reserva de vagas para a população pobre, negra e indígena em todas as universidades públicas federais e institutos técnicos federais brasileiros.

Estipulou-se a porcentagem mínima de $50 \%$ das vagas destinadas a estudantes que tenham cursado todo o Ensino Médio em escolas públicas, dentre eles negros e indígenas, proporcionais ao número desses grupos de pessoas que vivem no estado onde está localizada a universidade. Posteriormente, o projeto foi sancionado pela presidente Dilma Rousseff, passando a expressarse como lei, a chamada Lei de Cotas. Cabe ressaltar que dos $50 \%$ das vagas, $25 \%$ serão preenchidas considerando o critério de renda e a outra metade, $25 \%$, atenderá a critérios raciais. 
A entrada na universidade é um meio de superação diante de séculos de exclusão dos negros dos bancos acadêmicos. Quando a universidade, por meio de programas de ações afirmativas, passa a atender às necessidades de diversos grupos, está assumindo um compromisso com a sociedade e dela começa a fazer parte, deixando de priorizar apenas um segmento da população. Com isso, a presença de diversos grupos na universidade deve levar a mudanças de ideologias, teorias e metodologias no que concerne à produção de conhecimentos, além de fomentar um redimensionamento das atividades acadêmicas e científicas (SILVA, 2003).

\section{O INGRESSO DO ESTUDANTE NEGRO NO ENSINO SUPERIOR}

Ao analisar, durante a pesquisa ${ }^{2}$, processos educativos decorrentes da prática social ${ }^{3}$ da vida universitária, vimos que estes não estão relacionados apenas aos estudos exigidos no nível de Ensino Superior de educação, mas sim às inúmeras experiências decorrentes da entrada na universidade, seja nas relações com professores, estudantes, funcionários, seja na utilização da moradia estudantil, da biblioteca, em festas, nos jogos universitários, seja na participação em grupos de estudo e pesquisa, entre outros que o ambiente acadêmico põe à disposição. Constitui-se como uma nova fase na vida dos estudantes, pautada por dificuldades, desafios e descobertas.

É a partir das experiências que vivenciamos nas práticas sociais, juntamente com outras pessoas, que decorrem novos e renovados processos educativos.

Oliveira e colegas (2009) esclarecem que há práticas sociais que visam a transformação de realidades injustas, mas também pode acontecer de se direcionarem à manutenção de desigualdades, gerando processos educativos opressores para alguns.

Entende-se que a manutenção das desigualdades pode ocorrer quando práticas sociais são pautadas por hierarquias entre as pessoas, classificandoas, por exemplo, como mais ou menos bem informadas, mais ou menos inteligentes, mais ou menos capazes, mais ou menos bonitas e assim por diante. Tais hierarquias, notadamente as raciais, mas não exclusivamente, geram e perpetuam desigualdades.

Ver Oliveira (2013).

No presente estudo, "Práticas sociais decorrem de/e geram interações entre os indivíduos e entre eles e os ambientes natural, social, cultural em que vivem. Desenvolvem-se no interior de grupos, de instituições, com o propósito de produzir bens, transmitir valores, significados, ensinar a viver e a controlar o viver [...]" (OLIVEIRA et al., 2009, p. 4). 
O Ensino Superior é um bom exemplo disso, já que, até a adoção de políticas de ações afirmativas nas universidades, privilegiavam-se estudantes com perfil homogêneo e elitista.

A entrada de estudantes negros na universidade é a conquista de uma luta travada pelo Movimento Negro que, por meio de políticas de ações afirmativas, vem gerando transformações na atual realidade das universidades e da sociedade brasileira.

Mas os estudantes estão podendo construir e fortalecer suas identidades negras $^{4}$ e seu pertencimento étnico-racial, enraizado em culturas africanas, na vida universitária?

A construção das identidades é um processo histórico e político e, apesar das inúmeras identidades que uma pessoa possa elaborar, é possível construir uma identidade negra unificadora de caráter político, elaborada de acordo com experiências semelhantes de violência e desigualdades vividas pela população negra em nosso país.

A construção da identidade negra, assim como a construção de qualquer identidade, é um processo dinâmico iniciado na família e modificado de acordo com as interações e experiências dos indivíduos ao longo da vida por meio dos vários grupos de que faz parte, como, por exemplo, amigos e escola (GOMES, 2005; SILVA, 1995).

Tais interações são processos dialógicos, situados historicamente, que permitem a formação do conjunto de identidades que nos constituem, ou seja, são processos contínuos de confronto e identificação com outras pessoas, realidades, pontos de vista e estão sujeitos a transformações. Em um processo contínuo e inacabado, a construção das identidades é interpelada por inúmeras influências, positivas ou negativas, fazendo-nos assumir diferentes identidades de acordo com o momento e/ou lugar em que estamos (GOMES, 1995; SILVA, 1995; CASTELLS, 2008; TAYLOR, 1994, HALL, 2005).

Construir uma identidade negra vai muito além da fenotipia e é um posicionamento político, podendo ser um processo difícil, já que a construção das identidades, como já foi dito, se dá em relações sociais nem sempre cordiais “[...] e a relação é [muitas vezes] conflitiva quando se trata de negros e brancos” (SILVA, 1995, p. 68).

4 Ao utilizar o adjetivo negras para designar identidades, não nos referimos a marcas biológicas, mas a raízes e visões de mundo de origem africana. 
No mesmo sentido, Andrade (2006) afirma que a ideologia da democracia racial faz com que haja um sentimento de inferioridade introjetado nos negros e de superioridade nos não negros, o que interfere de modo incisivo e negativo na construção da identidade negra.

Isso ocorre porque os negros estão imersos em um discurso que foi elaborado pelo branco europeu, adotado hoje por muitos brasileiros de acordo com interesses do dominador, e não em representações positivadas sobre sua origem e modos de ser.

Estando o negro desfavorecido, fortalecer o sentimento de grupo negro se faz muito importante e isso se dá por meio da valorização do pertencimento étnico-racial.

Segundo Nogueira (2008), o sentimento de pertença é a forma como a pessoa se sente, pensa e age em relação ao seu grupo étnico-racial, sendo que tal pertencimento apresenta-se como um dos componentes da identidade étnicoracial. No Brasil, a constituição do pertencimento étnico-racial ocorre de acordo com a maneira como são estabelecidas as relações raciais em nosso país, ou seja, em meio a tensões.

[...] a construção do pertencimento e da identidade étnico-raciais ocorre em meio a tensões mediadas, de um lado, por ideologias criadas por um grupo que detém o poder e visa enfraquecer outros grupos diversos de si; de outro lado, por movimentos de resistência das culturas populares que estrategicamente contestam a opressão e dominação que lhes são impostas (NOGUEIRA, 2008, p. 125).

Assim como na sociedade em geral, o racismo também pode ser manifestado no meio acadêmico, podendo surtir uma relação desigual entre os diferentes grupos e uma “[...] pressão social e institucional para que ele(a) deixe de ser o que é, deixe de ser negro(a) e busque tornar-se branco(a), pois [a universidade] é um meio majoritariamente branco e exige posturas de branquitude" (NOGUEIRA, 2008, p. 33). Sobre isso, Teixeira (2003, p. 116) pondera que a Universidade “[...] também é vista, por alguns negros, como responsável por uma possível perda da identidade negra”.

Desse modo:

A universidade é um ambiente que força ou pressiona as pessoas negras a deixarem de ser quem são. Esta instituição tende a enquadrar os(as) negros(as) nos estereótipos da música ou das artes para aceitá-los(as) com mais facilidade ou, ao contrário, oferece resistência para aceitá-los(as) em outros perfis que não são considerados "lugares de negros(as)" (NOGUEIRA, 2008, p. 80). 
Se a pessoa negra deixa de assimilar-se por tais pressões, muitos dirão que “[...] a maior convivência no meio branco é que faz com que os negros não se vejam e queiram embranquecer" (TEIXEIRA, 2003, p. 78). Essa é uma visão recorrente do senso comum, pretendendo culpabilizar a pessoa negra e, assim, a universidade se eximiria de sua postura perversa de imposição de modelos eurocentrados.

\section{DESENVOLVIMENTO DA PESQUISA}

Buscando-se identificar processos educativos na vida universitária que contribuem ou prejudicam a construção e o fortalecimento da identidade negra e o pertencimento étnico-racial, junto a estudantes negros ingressantes por meio de reserva de vagas no Ensino Superior, além de apontar, diante da perspectiva dos estudantes negros ingressantes por meio de reserva de vagas, sugestões que possam contribuir com o Programa de Ações Afirmativas da UFSCar na busca de estratégias para o combate do racismo, a pesquisa que deu origem a este artigo pautou-se na seguinte questão: Quais processos educativos, na vida universitária, contribuem ou prejudicam a construção e o fortalecimento da identidade negra e o pertencimento étnico-racial de estudantes negros ingressantes por meio de reserva de vagas?

A presente pesquisa utilizou-se de uma metodologia inspirada na Fenomenologia, que, de acordo com Merleau-Ponty (2006), se ocupa das experiências vividas. Ou seja, entende que os significados que damos a nós mesmos, aos outros, à vida, enfim, ao mundo em que vivemos se constroem e se mostram nas experiências vividas, no dia a dia.

São os participantes da pesquisa que fornecem direções para captar o fenômeno estudado, isto é, aquilo que se mostra, que se manifesta. No presente caso, o fenômeno são processos educativos de construção e fortalecimento da identidade negra e do pertencimento étnico-racial em um ambiente universitário. Assim, busca-se aproximação à essência do fenômeno estudado.

Segundo Garnica (1999, p. 116):

A essência do que se procura nas manifestações do fenômeno nunca é totalmente apreendida, mas a trajetória da procura possibilita compreensões. Fenômenos nunca são compreendidos sem que sejam inicialmente interrogados: disponiveis na percepção, são questionados e, na perspectiva fenomenológica, qualquer forma de manifestação ou objetividade implica um relacionamento intersubjetivo. 
É na relação intersubjetiva entre pesquisadora e participantes da pesquisa que se constrói a objetividade dos resultados que encontramos.

Os dados foram coletados por meio de entrevistas semiestruturadas que combinam perguntas abertas e fechadas, ou seja, é um tipo de entrevista que dá margem a que o entrevistado discorra mais livremente sobre o assunto proposto. Porém, para um melhor andamento da entrevista, há o mínimo possivel de intervenções por parte do entrevistador, a fim de não interromper a sequência de pensamento do entrevistado (BONI; QUARESMA, 2005).

Entre os três entrevistados que aceitaram o convite para participar da pesquisa, enviado via e-mail a estudantes ingressantes por meio do Programa de Ações Afirmativas da UFSCar, estão duas mulheres e um homem, ingressantes nos anos de 2008, 2011, 2012 e pertencentes aos cursos de Engenharia Química, Pedagogia e Ciências Sociais, respectivamente.

0 número de participantes foi restrito porque a quantidade de estudantes negros na universidade no período da pesquisa ainda era reduzido, o que levou ao aceite de apenas três.

As entrevistas foram feitas de maneira individual, mediante agendamento prévio, e realizadas com base nas seguintes perguntas:

- O que leva você a declarar-se preto ou pardo?

- Ao declarar-se preto ou pardo, você se inclui no grupo designado negro. Você está reconhecendo que cultural e historicamente você está ligado a raízes africanas do Brasil? Como você vem construindo esse reconhecimento das raízes africanas na sua vida, no seu modo de ser?

- No seu percurso escolar, você sentiu dificuldades em manifestar seu pertencimento étnico-racial?

- Como a universidade o auxilia a fortalecer o seu pertencimento étnicoracial e em que dificulta ou o impede?

\section{RESULTADOS}

Seguindo a análise dos dados sob a forma de descrição compreensiva, as dimensões encontradas nas falas dos participantes e os significados atribuídos a cada uma das dimensões, no que refere à construção e fortalecimento da identidade negra e do pertencimento étnico-racial, foram as seguintes: família, corpo negro, postura política, ancestralidade negra, escola, universidade, racismo, discriminação, políticas de ações afirmativas, estudos da temática étnico-racial e convivência com pessoas negras. 
Pode-se constatar que processos educativos de construção e fortalecimento da identidade negra e do pertencimento étnico-racial, tanto os que contribuem quanto os que prejudicam tais construções, iniciam-se muito antes da entrada na universidade e em diferentes contextos.

A educação recebida no seio familiar fornece subsídios para que os participantes se fortaleçam enquanto pessoas negras, pois recebem elogios em relação a seus corpos, são encorajados a enfrentar o racismo e motivados a buscar seus direitos, como, por exemplo, o de compreender que políticas de ações afirmativas não se constituem em esmolas, nem em preconceito dos negros pelos próprios negros, como pretendem alguns.

O corpo negro, notadamente o cabelo crespo e a cor da pele, são alvos utilizados por pessoas racistas a fim de desqualificar uma pessoa negra. Segundo Gomes (2010), cabelo e cor da pele não são construídos apenas biologicamente, mas simbolicamente na estrutura social e cultural, sendo uma marca identitária, ou seja, que inclui pessoas dentro de um grupo étnico-racial.

Assim, apresentar corpo negro é, muitas vezes, passar por constrangimentos. Uma participante da pesquisa, sob a lógica de que ser bela é ser branca, conta que enfrentou racismo na adolescência devido a seus traços fenotípicos. Além de ser indicada como a única negra no ambiente escolar que frequentava, seu cabelo era alvo de desqualificações, o que fez a estudante realizar técnicas para alisar os cabelos a fim de identificar-se com o grupo de colegas.

Os estudos da questão étnico-racial, ocorridos na universidade e em participações em grupos do Movimento Negro, se juntam aos conselhos da família, fazendo com que a estudante perceba que o alisamento pode descaracterizá-la se for feito com o intuito de se aproximar do modelo branco, pois, como afirma Gomes (2005), o estilo do cabelo pode servir tanto para camuflar o pertencimento na tentativa de encobrir conflitos, alisando-os, por exemplo, como pode representar reconhecimento das raízes africanas e, como dito, servir de resistência.

A afirmação do corpo negro como forma de resistência mostra que a cor da pele influencia a declaração de um pertencimento étnico-racial, porém, apresentar tez escura não quer dizer que obrigatoriamente ocorra um pertencimento ligado às raízes africanas.

Afirmar-se negra ou negro por meio das características fenotípicas, em que se sobressai a dupla cabelo e cor de pele, passa por assumir resistência, já que no Brasil, como afirma Nogueira (2006), o preconceito é de marca, referente 
à fenotipia, aos traços físicos, havendo uma classificação hierarquizada das pessoas diante da cor que possuem. Assim, possuir tez escura significa, em algum momento, ser discriminado.

A pesquisa apontou, portanto, que apresentar tez escura é um caminho para a construção da identidade negra e do pertencimento étnico-racial de raiz africana, mas exige um posicionamento político.

Mais do que apresentar tez escura, para construir uma identidade negra e pertencimento étnico-racial é necessário assumir uma postura política, adquirida por meio de conscientização, isto é, do que significa ser negro em uma sociedade racista como a nossa.

Segundo Munanga (2004), adquirir consciência do papel do negro na sociedade passa pelo resgate da memória coletiva da comunidade negra. É necessário, pois, resgatar a real história da população negra do ponto de vista dessa população, e não uma história de preconceito ainda transmitida pela escola, ou seja, uma história cercada de omissões e racismo.

Os participantes da pesquisa, em suas experiências de construção de identidade negra e pertencimento étnico-racial, salientam a importância de terem tomado conhecimento dos processos histórico/ideológicos que foram construídos no Brasil e das representações que vêm desqualificando a população negra, tal como abordaram Andrade (2006) e Nogueira (2008).

Dessa forma, os participantes se veem competentes para criticar as representações que desqualificam a população negra, possibilitando lutar por seus direitos e manter posturas de resistência contra o racismo e a discriminação.

A aquisição de consciência étnica, entre os participantes, fora dos muros escolares não exime a escola de sua responsabilidade e de sua culpa. De sua responsabilidade, pois a escola tem o dever de valorizar a diversidade étnicoracial da população brasileira, e de sua culpa porque processos educativos ocorridos no meio escolar sempre estiveram permeados por racismo e discriminação, que têm deixado marcas constrangedoras nos estudantes.

O currículo escolar é um dos pontos de partida que deve sofrer mudanças se buscarmos a melhoria no ensino e nas relações sociais, notadamente relações étnico-raciais, ocorridas tanto no ambiente escolar como fora dele, já que tal currículo pauta-se em um modelo que está a serviço das classes dominantes, tornando seus conhecimentos hegemônicos e assim excluindo, desqualificando 
e inferiorizando saberes de outros grupos sociais (LOPES, 1995).

A decisão pelo ingresso na universidade por meio de políticas de ações afirmativas caracteriza-se como uma reafirmação de um posicionamento político adquirido antes mesmo do ingresso na universidade, ou seja, de dizer-se negro numa sociedade que se quer branca.

Salienta-se que tal posicionamento é muito questionado tanto no interior como fora da universidade.

Os questionamentos vêm de pessoas que se opõem às políticas de ações afirmativas, expressando os mais variados argumentos de que estudantes negros não poderiam aceitar reserva de vagas para o ingresso na universidade, pois não são inferiores aos demais e tal decisão seria um preconceito dos próprios negros.

Mesmo diante de muitos opositores que buscam evitar que a população negra alcance ascensão social, os participantes da pesquisa ingressaram na universidade por incentivo da família, de amigos e por meio de leituras a respeito de políticas de ações afirmativas que esclarecem as reais necessidades de tais políticas. Ou seja, superam equivocadas acusações de uma suposta inferioridade dos negros ao ingressarem na universidade por meio de reserva de vagas.

Conscientes de que os argumentos de opositores são equivocados, os participantes veem o ingresso na universidade como motivo de dupla vitória, ou seja, passar no vestibular e provar o contrário àqueles que os tinham desestimulado. A concepção que tinham, reafirmada com frequência, era a de que os estudantes negros não seriam capazes de ingressar em uma universidade pública. Difundia-se a ideia de que oriundos de escolas públicas e negros não teriam oportunidades de acesso à universidade pública, pois não haviam cursado escola particular nem pertenciam à elite. E, de fato, o público da universidade era, até então, muito homogêneo.

Cursar o Ensino Superior apresentava-se como uma possibilidade distante da realidade de estudantes negros e as políticas de ações afirmativas, por meio de reserva de vagas, colocam essa possibilidade mais próxima desses estudantes. 0 fato de existir reserva de vagas fortaleceu a confiança dos participantes, que conseguiram enxergar possibilidades de ingressar no Ensino Superior público. 
Para estudantes negros que foram convencidos de que não poderiam ingressar na universidade pública, a existência de reserva de vagas lhes deu segurança. $O$ fato de saberem que seriam respeitados lhes forneceu incentivo para realizar o vestibular, pois, ao contrário de antes, sabiam que havia um lugar destinado a eles na universidade. As políticas de ações afirmativas promovem, portanto, um sentimento de que o estudante negro pode fazer parte do ambiente acadêmico.

Além de os estudantes negros conceberem as políticas de ações afirmativas como uma grande vitória para a população negra, destacam serem tais políticas decisivas para o seu ingresso na universidade. Compreendem a importância de ter acesso ao Ensino Superior e de acessar a produção de conhecimento da academia como meio de ascensão social. Mais do que isso, a pesquisa aponta que manter um posicionamento político enquanto negro na universidade é enfrentar embates pela afirmação de toda uma população.

Apesar da implementação de programas de ações afirmativas que promovem o ingresso de diversos grupos sociais na universidade, os dados da pesquisa apontam que nos currículos não houve mudanças a fim de contemplar tais grupos, ou seja, as aulas são ministradas de acordo com currículos voltados à educação de um grupo homogêneo, com literaturas e concepções eurocentradas, desconsiderando outros saberes, de matrizes africana e indígena, por exemplo.

Causa incômodo nos estudantes negros não terem sua história contemplada no currículo acadêmico, melhor dizendo, incomoda o fato de apenas um tipo de conhecimento ser valorizado, e somente alguns autores serem estudados, sendo eles sempre europeus e estadunidenses.

A omissão de professores e professoras diante de outros tipos de saberes se constitui em perpetuação do racismo. Dessa forma, o currículo utilizado mostra-se preconceituoso e excludente. É por meio da omissão que as desigualdades continuam a se perpetuar sem haver questionamentos. Parece que os currículos não se modificaram.

Em se tratando de estudos, os estudantes negros mostram-se conscientes diante de situações racistas, buscando fora da sala de aula o que nela não é contemplado, seja em grupos de estudos de temática étnico-racial, seja em disciplina optativa, da qual poucos estudantes não negros mostram interesse em participar. Por meio dos estudos da temática étnico-racial sentem-se mais 
fortalecidos e conseguem expressar seus posicionamentos perante situações ocorridas no ambiente acadêmico que buscam induzi-los a ignorar suas identidades e o pertencimento étnico-racial.

Estando mais conscientes do racismo que os acomete na academia, conseguem, de certo modo, se proteger criando estratégias para suportar o racismo ao mesmo tempo que mantêm um posicionamento de enfrentamento, sem entrar, porém, em confrontos explícitos que poderiam ser prejudiciais, como discussões com professores, por exemplo.

Muitos professores buscam questionar em sala de aula quem é cotista. Isso não é um problema para os participantes da pesquisa, pois não veem constrangimento em se autodeclararem negros e cotistas, se questionados. O problema, segundo eles, está na compreensão de alguns professores que esperam que eles realmente apresentem rendimento inferior aos demais estudantes. Parecem querer impingir no estudante negro uma marca, para que em qualquer "deslize" se possa afirmar que as profecias de que o nível da academia decairia se cumpriram.

Pode-se considerar que tais professores buscam apagar a pessoa negra do ambiente universitário, ou seja, se é bom, não pode ser negro. Induzir o estudante negro a cogitar a possibilidade de ele se tornar branco também se caracteriza como genocídio, tal como dizia Abdias Nascimento (1978).

No mesmo sentido, Silva (2003, p. 40) nos diz que:

[...] quanto mais as pessoas se aproximarem do modelo dominante branco/europeu, maior será o seu valor; quanto mais se distanciarem do modelo negro/africano, maiores serão as chances de serem aceitas no mundo de domínio branco.

Daí a insistência de professores e, às vezes, colegas, ao dizerem: "Mas você não é negra. Você vai tão bem!”.

Pode-se constatar, na pesquisa, que os estudantes negros apresentam um senso de coletividade muito fortalecido. Logo, quando professores questionam sua identidade negra, o teor racista da abordagem abrange toda a comunidade negra, ou seja, o racismo, apesar de algumas vezes ser direcionado a apenas uma pessoa, se reflete em todas as outras que possuem a mesma fenotipia, a mesma ancestralidade, o mesmo posicionamento político, o mesmo pertencimento étnico-racial. Na academia não vão individualizar o estudante, ao contrário, colocarão todos no grupo supostamente intitulado "negros da reserva de vagas". 
Do mesmo modo, quando uma participante se preocupa com seu rendimento, ela não o faz pensando individualmente, mas sim pensando nos benefícios que isso trará a todos os estudantes negros. Ou seja, se um estudante negro obtiver rendimento ruim, isso se refletirá em todo o grupo de estudantes negros ingressantes por meio de reserva de vagas. 0 contrário também se aplica. 0 êxito de um estudante negro refletirá em todos os estudantes de seu grupo.

Retomando a agressão proferida por alguns professores diante da identidade negra e do pertencimento étnico-racial dos estudantes, Gomes (1995, p. 83) pondera que os negros muitas vezes assimilavam valores e a cultura do grupo eurocêntrico branco, acarretando desestímulo em relação a seu grupo e negação da herança africana, pois tal ideologia “[...] o leva a perceber o seu grupo de origem como referência negativa, lugar de onde ele deverá se distanciar [...]”.

Isso parece não ocorrer entre os estudantes da pesquisa, que a cada ataque buscam formas de sobreviver e de se impor na academia.

Outra forma de racismo praticada por professores se traduz em questionar e desqualificar a posição socioeconômica de estudantes negros. Afirmar que um estudante não tem possibilidade de estar em um curso de Engenharia porque não tem condições econômicas de comprar um computador se traduz, para os estudantes negros, como a afirmação de que eles são intrusos naquele ambiente, e de que tal curso é impossível de ser realizado por pessoas pobres e, nesse caso, também por pessoas negras. Confirma-se o que Munanga (2003) já afirmava, que os estudantes negros são duas vezes mais discriminados do que estudantes brancos pobres, pela questão racial e pela questão econômica. A universidade, na medida em que acolhe os estudantes, tem de criar condições para que realizem o curso com sucesso.

A discriminação racial também é provocada por parte dos colegas de classe. Uma participante afirma que os demais estudantes de sua turma, não negros, não a aceitam como pessoa negra, pois novamente seu bom desempenho não condiz com sua cor. Porém, por manter sua postura política enquanto mulher negra, reforçando sua identidade e seu pertencimento étnico-racial, os demais estudantes a excluem, ou seja, procuram não realizar trabalhos em grupo com ela. Segundo a participante, o que talvez provoque tal discriminação seria o fato de possuírem vivências, experiências e concepções de vida muito distintas, experiências as quais ela não possui e que são valorizadas na academia, como, por exemplo, apresentar um vasto currículo 
de viagens e ter domínio de línguas estrangeiras. Além disso, afirma que suas prioridades diferem muito em relação à dos colegas de classe. Logo, ao resistir em reproduzir as concepções dos demais estudantes, é excluída.

O posicionamento político dos estudantes negros não é muito bem compreendido por professores e demais estudantes, o que os faz buscarem reduto na academia junto de outras pessoas que os compreenda, que os incentive e que passam, ou já passaram pelas mesmas dores, sendo esses outros estudantes negros de diferentes cursos e de distintos anos de ingresso.

Buscar apoio junto a outros estudantes negros é uma estratégia utilizada pelos participantes, seja em grupos de estudos, seja em festas com temática africana, seja em grupos de moradores do alojamento estudantil. Tais agrupamentos se constituem em formas de resistência diante de todos os acontecimentos narrados pelos estudantes negros no meio acadêmico.

Cabe destacar que a existência de grupos negros na universidade não se reflete numa cisão racial, entre negros e brancos, gerando um aumento do racismo por meio da tensão entre ambos os grupos, como pretendem Fry e Maggie (2004), mas sim como uma maneira de estudantes negros se fortalecerem por meio da união e passarem a ser respeitados em suas especificidades.

A formação de grupos é válida desde que tais grupos não se isolem e não sejam isolados pelos demais. Assim, a formação de grupos negros visando apoio e fortalecimento não deve buscar isolamento em relação a pessoas não negras, já que estas também podem se configurar em aliadas na luta contra o racismo e a discriminação.

A formação de grupos de estudantes negros visa um fortalecimento que não é oferecido pelo Programa de Ações Afirmativas da UFSCar. Os estudantes negros não sentem o apoio que esperavam, talvez pela falta de divulgação do Programa no campus. Assim, por mais que o Programa se mostre disposto a atender qualquer estudante do campus, seja da reserva de vagas ou não, parece haver necessidade de maior apoio aos estudantes negros, visto que estão sofrendo racismo no campus. 


\section{CONCLUSÃO}

A pesquisa proporcionou identificar processos educativos que contribuem ou que prejudicam a construção e o fortalecimento da identidade negra e do pertencimento étnico-racial entre estudantes negros, ingressantes por meio de reserva de vagas na universidade. Ela também nos forneceu indicativos do que precisa ser transformado na universidade para que os estudantes negros possam desfrutar a vida universitária de modo satisfatório. Assim, identificaram-se propostas dos estudantes negros a fim de contribuir para programas de ações afirmativas, sendo elas: necessária mudança no currículo, formação de professores para a educação das relações étnico-raciais, maior divulgação do Programa no campus, melhoria nas estratégias de aproximação do Programa com estudantes negros e aumento no número de bolsas.

Apesar das políticas de ações afirmativas serem consideradas como decisivas para o ingresso dos estudantes na universidade, o Programa de Ações Afirmativas ainda não corresponde ao esperado por eles, ou seja, enquanto integrantes do grupo negro na universidade, não sentem o apoio necessário.

Apesar da existência de atendimento e acolhimento por parte do Programa de Ações Afirmativas, voltado a todos os estudantes, independentemente de ser ou não ingressante por meio de reserva de vagas, como já dito, sabe-se que a maior procura pelo apoio fornecido ocorre entre estudantes indígenas. Tornase importante, portanto, buscar compreender as causas do distanciamento dos estudantes negros.

A pesquisa mostrou que muitas mudanças precisam ocorrer na universidade, mentalidades precisam se transformar. Cabe aos cursos, por meio de seus coordenadores e professores, uma aproximação com a diversidade, bem como uma reeducação de estudantes ingressantes por ampla concorrência para que reconheçam que os estudantes negros ingressantes por meio de reserva de vagas não são inferiores. Assim, o tratamento deve ser igualitário aos estudantes, respeitando-se suas diferenças.

Diante das inúmeras conquistas da população negra por seu direito à educação, espera-se que não tenhamos mais estudantes negros que, ao passar em frente a uma universidade, sintam-se excluídos daquele ambiente, pois saberão que por direito aquele espaço foi por eles conquistado. Com isso, seus pares terão oportunidade de ingressar no Ensino Superior público e esta será, a cada dia mais, a realidade educacional de estudantes negros e negras de nosso país. 
O desafio, portanto, não será mais o ingresso, mas sim garantir que os conhecimentos e a história da população negra sejam valorizados na academia.

Não podemos aceitar que professores permaneçam seguindo antigos currículos e que mantenham um pensamento pautado por estereótipos racistas perante os estudantes da reserva de vagas. Também não podemos permitir que estudantes não negros excluam os estudantes negros por não compactuarem com seus posicionamentos políticos.

Espera-se que a pesquisa tenha contribuído como uma ferramenta de luta, expressando posicionamentos de estudantes negros que reafirmam todos os dias os seus direitos à educação de qualidade. Que os dados aqui presentes sirvam como evidenciações do momento atual dos estudantes negros na universidade, pois silenciar é deixar as coisas como estão. Ou seja, se os problemas não emergirem para a busca de soluções, eles irão permanecer e poderão aumentar.

Assim, é necessário um acompanhamento constante na busca de soluções e melhorias visando a equidade. 


\section{Black students admission to university through quota system}

Abstract: This article results from a Master's degree research carried out among self-declared Black students admitted to Federal University of São Carlos through an affirmative actions program (quota system). This research aimed at identifying educational processes originating in university life that concur to and impair building and strengthening Black identity and Africanrooted ethnic-racial belonging among such students, as well as mentioning suggestions that may add to UFSCAR Affirmative Actions Program in their search for strategies in fighting racism. Data collection was made through half-structured interviews with three self-declared Blacks, two women and one man from different courses.

Keywords: Affirmative actions. Black students. Black identity. Ethnic-racial belonging. 


\section{Estudiantes negros ingresantes en la universidad por medio de reserva de plazas Resumen:}

Resumen: El presente artículo es el resultado de una investigación de maestría realizada con estudiantes que se declaran negros ingresantes en la Universidad Federal de São Carlos por medio de un programa de acciones afirmativas de reservas de plazas. La investigación tuvo como objetivos identificar procesos educativos originados en la vida universitaria que contribuyen y perjudican la construcción y el fortalecimiento de la identidad negra y la pertenencia étnicoracial de raíz africana, junto a tales estudiantes, además de señalar sugerencias que contribuyan con el Programa de Acciones Afirmativas de la UFSCar en la búsqueda de estrategias de combate al racismo. La recopilación de datos ocurrió por medio de entrevistas semiestructuradas con tres estudiantes que se declaran negros, dos mujeres y un hombre de distintas carreras.

Palabras clave: Acciones afirmativas. Estudiantes negros. Identidad negra. Pertenencia étnico-racial 


\section{REFERÊNCIAS}

ALMEIDA, Wilson Mesquita de. 0 ProUni e a "democratização do ensino superior": explorações empíricas e conceituais. [s/d.]. Disponível em: http:// www.anped.org.br/33encontro/app/webroot/files/file/Trabalhos\%20em\%20 PDF/GT11-6232--Int.pdf. Acesso em: jul. 2012.

ANDRADE, Paulo Sérgio de. Pertencimento étnico-racial e ensino de história. 2006. Dissertação (Mestrado em Educação) - Programa de Pós-graduação em Educação da Universidade Federal de São Carlos, São Carlos, 2006.

BONI, Valdete; QUARESMA, Silvia Jurema. Aprendendo a entrevistar: como fazer entrevistas em Ciências Sociais. Revista Eletrônica dos Pós-Graduandos em Sociologia Política da UFSC, v. 2, n. 1, p. 68-80, jan.-jul. 2005. Disponível em: http://www.journal.ufsc.br/index.php/emtese/. Acesso em: out. 2012.

BORGES, Maia Célia; AQUINO, Orlando Fernandez. Educação superior no Brasil e as políticas de expansão de vagas do Reuni: avanços e controvérsias. Educação: Teoria e Prática, v. 22, n. 39, abr. 2012. Disponível em: http://www. periodicos.rc.biblioteca.unesp.br/index.php/educacao/article/view/4584. Acesso em: ago. 2012.

CARVALHO, Cristina Helena Almeida de. O Prouni no governo Lula e o jogo político em torno do acesso ao ensino superior. Educ. Soc., Campinas, v. 27, n. 96 - Especial, p. 979-1000, out. 2006. Disponível em: http://www.cedes. unicamp.br. Acesso em: jul. 2012.

CASTELLS, Manuel. 0 poder da identidade. A era da informação: economia, sociedade e cultura. Tradução Klauss Brandini Gerhardt. 6. ed. São Paulo: Paz e Terra, 2008. v. 2.

FRY, Peter; MAGGIE, Yvonne. Cotas raciais: construindo um país dividido? Econômica: Revista da Pós-Graduação em Economia da UFF, Dossiê: Ação afirmativa. Niterói, v. 6, n. 1, 2004. Disponível em: http://www.proppi.uff.br/ revistaeconomica/sites/default/files/. Acesso em: jan. 2013.

GARNICA, Antônio Vicente Marafioti. Educação, matemática, paradigmas, prova rigorosa e formação do professor. In: BICUDO, Maria Aparecida Viggiani; CAPPELLETTI, Isabel Franchi (org.). Fenomenologia: uma visão abrangente da educação. São Paulo: Editora Olho d’água, 1999.

GOMES, Nilma Lino. Alguns termos e conceitos presentes no debate sobre 
relações raciais no Brasil: uma breve discussão. In: MINISTÉRIO DA EDUCAÇÃO. Educação anti-racista: caminhos abertos pela Lei Federal n. 10.639. Secretaria de Educação Continuada, Alfabetização e Diversidade. Brasília: MEC, 2005. (Coleção Educação Para Todos).

GOMES, Nilma Lino. A mulher negra que vi de perto. Belo Horizonte: Mazza Edições, 1995.

GOMES, Nilma Lino. Uma dupla inseparável: cabelo e cor da pele. In: BARBOSA, Lúcia M. de Assunção; SILVA, Petronilha Beatriz Gonçalves; SILVÉRIO, Válter Roberto (org.). De preto a afrodescendente: trajetos de pesquisa sobre 0 negro, cultura negra e relações étnico-raciais no Brasil. São Carlos: EdUFSCar, 2010.

GONÇALVES, Luiz Alberto Oliveira; SILVA, Petronilha Beatriz Gonçalves. Movimento Negro e educação. Rev. Bras. Educ. [on-line], n. 15, p. 134-158, set./out./nov./dez. 2000. Disponível em: http://www.scielo.br/pdf/rbedu/ n15/n15a09.pdf. Acesso: jan. 2013.

HALL, Stuart. A identidade cultural na pós-modernidade. Tradução Tomaz Tadeu da Silva, Guaracira Lopes Louro. 10. ed. Rio de Janeiro: DP\&A, 2005.

INSTITUTO BRASILEIRO DE GEOGRAFIA E ESTATÍSTICA (IBGE). Síntese de indicadores sociais: uma análise das condições de vida da população brasileira. 2010. Disponível em: http://www.ibge.gov.br. Acesso em: jan. 2013.

LIMA, Heloisa Pires. A imagem negra no portal para o sucesso: 0 antes, o durante e o depois do vestibular. In: ANDRADE, Rosa Maria T.; FONSECA, Eduardo F. (org.). Aprovados!: cursinho pré-vestibular e população negra. São Paulo: Selo Negro Edições, 2002.

LOPES, Ademil. Escola, socialização e cidadania: um estudo da criança negra numa escola pública de São Carlos/SP. São Carlos: EDUFSCar, 1995.

MERLEAU-PONTY, Maurice. Fenomenologia da percepção. Tradução Carlos Alberto Ribeiro de Moura. 3. ed. São Paulo: Martins Fontes, 2006.

MUNANGA, Kabengele. Políticas de ação afirmativa em benefício da população negra no Brasil: um ponto de vista em defesa de cotas. In: SILVA, Petronilha Beatriz Gonçalves e; SILVÉRIO, Valter Roberto (org.). Educação e ações afirmativas: entre a injustiça simbólica e a injustiça econômica. Brasília: Instituto Nacional de Estudos e Pesquisas Educacionais Anísio Teixeira, 2003. 
MUNANGA, Kabengele. Uma abordagem conceitual das noções de raça, racismo, identidade e etnia. In: BRANDÃO, André Augusto P. Programa de educação sobre o negro na sociedade brasileira. Niterói: Editora da Universidade Federal Fluminense, 2004.

NASCIMENTO, Abdias do. 0 genocídio do negro brasileiro: processo de um racismo mascarado. Prefácio à edição nigeriana de Wole Soyinka; prefácio de Florestan Fernandes. Rio de Janeiro: Paz e Terra, 1978. (Coleção Estudos Brasileiros, v. 30).

NASCIMENTO, Tarcísio Antônio do. Expectativa de jovens negros quanto ao acesso à universidade: o caso de uma escola da Zona Norte de São Paulo. 2006. Dissertação (Mestrado) - Universidade Federal de São Carlos, São Carlos, 2006.

NEVES, Clarissa Eckert Baeta. A estrutura e o funcionamento do ensino superior no Brasil. In: SOARES, Maria Susana Arrosa (coord.). A educação superior no Brasil. Porto Alegre: Instituto Internacional para a Educação Superior na América Latina e no Caribe (lesalc) - Unesco Caracas, 2002. Disponível em: http://unesdoc.unesco.org/images/0013/001393/139317por. pdf. Acesso em: jun. 2012.

NOGUEIRA, Oracy. Preconceito racial de marca e preconceito racial de origem: sugestão de um quadro de referência para a interpretação do material sobre relações raciais no Brasil. Tempo Social - Revista de Sociologia da USP, v. 19, n. 1, p. 287-308, nov. 2006. Disponivel em: http://www.scielo.br/pdf/ts/ v19n1/a15v19n1.pdf. Acesso em: set. 2012.

NOGUEIRA, Simone Gibran. Processos educativos da Capoeira Angola e construção do pertencimento étnico-racial. Dissertação (Mestrado) Universidade Federal de São Carlos, São Carlos, 2008.

OLIVEIRA, Juliana Augusta Nonato de. Estudantes negros ingressantes na universidade por meio de reserva de vagas: um estudo sobre processos educativos de construção de identidade negra e pertencimento étnicoracial no ensino superior. 2013. 111f. Dissertação (Mestrado em Educação) - Programa de Pós-graduação em Educação da Universidade Federal de São Carlos, São Carlos, 2013. Disponível em: http://repositorio.ufscar.br. Acesso em: jan. 2019.

OLIVEIRA, Maria Waldenez; SILVA, Petronilha Beatriz Gonçalves; GONÇALVES 
JUNIOR, Luiz; MONTRONE, Aida Victória; JOLY, Ilza Zenker Leme. Processos educativos em práticas sociais: reflexões teóricas e metodológicas sobre pesquisa educacional em espaços sociais. In: REUNIÃO DA ANPED, 32., 2009, Caxambu. Anais [...]. Caxambu: Anped, 2009.

QUEIROZ, Delcene Mascarenhas. Cor e seletividade no ensino superior. In: BARBOSA, Lúcia M. de Assunção; SILVA, Petronilha Beatriz Gonçalves e; SILVÉRIO, Valter Roberto. (org.). De preto a afrodescendente: trajetos de pesquisa sobre o negro, cultura negra e relações étnico-raciais no Brasil. São Carlos: EdUFSCar, 2010.

SILVA, Cidinha da. Definições de metodologias para seleção de pessoas negras em programas de ação afirmativa em educação. In: SILVA, Cidinha da (org.). Ações afirmativas em educação: experiências brasileiras. São Paulo: Summus, 2003.

SILVA, Consuelo Dores. Negro, qual é o seu nome? Belo Horizonte: Mazza Edições, 1995.

SILVA, Petronilha Beatriz Gonçalves e. Ações afirmativas para além das cotas. In: MOEHLECK, Sabrina; SILVÉRIO, Valter Roberto. Ações afirmativas nas políticas educacionais: o contexto pós-Durban. São Carlos: EdUFSCar, 2009.

TAYLOR, Charles. Multiculturalismo: examinando a política de reconhecimento. Tradução Marta Machado. Lisboa: Instituto Piaget, 1994. (Coleção: Epistemologia e sociedade).

TEIXEIRA, Moema de Poli. Negros na universidade: identidade e trajetória de ascensão social no Rio de Janeiro. Rio de Janeiro: Pallas, 2003.

\section{SOBRE AS AUTORAS:}

Juliana Augusta Nonato de Oliveira é mestre em Educação pela Universidade Federal de São Carlos (UFSCar). Atua como professora de Ensino Fundamental na rede municipal de São Carlos.

E-mail:nonato6juliana@gmail.com

Petronilha Beatriz Gonçalves e Silva é doutora em Educação pela Universidade Federal do Rio Grande do Sul (UFRGS). Atua como professora emérita da UFSCar.

E-mail:pbgs@terra.com.br 
Recebido em: dezembro de 2018

Aprovado em: abril de 2019 